\title{
PENGARUH SUDUT KEMIRINGAN LERENG TERHADAP ANGKA STABILITAS LERENG TANAH KOHESIF BERDASARKAN KURVA TAYLOR DAN SOFTWARE GEO5
}

\author{
Andrias Suhendra Nugraha ${ }^{1}$, Adi Kurniawan Sutanto \\ ${ }^{1}$ Dosen Program Studi Teknik Sipil, Fakultas Teknik, Universitas Kristen Maranatha \\ dan Mahasiswa Program Studi Program Profesi Insinyur, Institut Teknologi Bandung \\ Email: andrias.sn@eng.maranatha.edu; andrias.sn@students.itb.ac.id \\ ${ }^{2}$ Alumnus Program Studi Teknik Sipil, Fakultas Teknik, Universitas Kristen Maranatha \\ Email: pecodriver@yahoo.co.id
}

\begin{abstract}
ABSTRAK
Perkembangan software dalam bidang geoteknik khususnya pada analisis stabilitas lereng akan mempermudah analisis dan juga memberikan tingkat akurasi analisis yang lebih baik dari metode konvensional. Studi ini bertujuan untuk menganalisis pengaruh sudut kemiringan lereng $(\beta)$ terhadap angka stabilitas (Ns) pada lereng tanah kohesif homogen berdasarkan kurva Taylor dan analisis output software Geo5. Jenis tanah kohesif pada lereng adalah lempung dengan konsistensi medium (medium clay). Sudut kemiringan lereng $(\beta)$ yang ditinjau lebih kecil dari $53^{\circ}$. Hasil studi menunjukkan bahwa salah satu keunggulan analisis stabilitas lereng dengan software Geo5 adalah dapat memberikan informasi mengenai lokasi slip circle atau circular slip surface, dimana hal ini tidak dapat diperoleh dari kurva Taylor. Sudut kemiringan lereng semakin besar, maka angka stabilitas semakin besar untuk setiap faktor kedalaman $\left(D_{f}\right)$ yang sama. Hal tersebut berlaku untuk analisis berdasarkan kurva Taylor maupun berdasarkan software Geo5. Selisih absolute angka stabilitas berdasarkan kurva Taylor terhadap hasil analisis software Geo5, berkisar antara $0.17 \%$ hingga 3.08\% untuk kondisi faktor jarak (n) antara 0 hingga 3. Angka stabilitas dipengaruhi juga oleh faktor kedalaman, dimana angka stabilitas akan meningkat seiring dengan meningkatkan faktor kedalaman.
\end{abstract}

Kata kunci: Angka stabilitas, Lereng tanah kohesif, Sudut kemiringan, Kurva Taylor, Geo5.

\begin{abstract}
The development of software in the geotechnical engineering, especially in the analysis of slope stability will facilitate the analysis and also provide a better level of accuracy than conventional methods. The study aim to analyze effect of stability number (Ns) to the slope of homogenous cohesion soils based on the Taylor's curve and software Geo5. Type of cohesive soil on the slope is medium clay. The slope angle ( $\beta$ ) observed less than $53^{\circ}$. The study results show that one of the advantages of slope stability analysis with Geo5 is that it can provide information about the location of the slip circle or circular slip surface, which cannot be obtained from the Taylor's curve. The greater the slope angle, the greater the stability number for each depth factor $\left(D_{f}\right)$. It applies to the analysis based on the Taylor's curve or based on Geo5. The absolute difference of stability number based on the Taylor's curve to the results based on the Geo5 software analysis ranged from $0.31 \%$ to $3.08 \%$ for the distance factor $(n)$ ranged from 0 to 3 . The stability number is also influenced by the depth factor, where the stability number will increase along with increasing depth factor.
\end{abstract}

Keywords: Stability Number, Slope of cohesion soils, Slope angle, Taylor's curve, Geo5.

\section{PENDAHULUAN}

Analisis stabilitas lereng dilakukan untuk mengevaluasi desain yang aman untuk lereng buatan manusia (human-made) atau lereng alami dan kondisi 
keseimbangan. Desain suatu lereng yang aman dan ekonomis dapat dimungkinkan dengan adanya perkembangan metode yang modern untuk pengujian tanah dan analisis stabilitas (Salunkhe et al., 2017).

Perkembangan software dalam bidang geoteknik khususnya pada analisis stabilitas lereng akan mempermudah analisis dan juga memberikan tingkat akurasi analisis yang lebih baik dari metode konvensional. Taylor (1937) mengusulkan suatu kurva desain untuk mengevaluasi faktor keamanan (factor of safety) lereng tanah yang homogen. Salah satu kelemahan dari kurva Taylor adalah tidak dapat menentukan lokasi slip circle (Stetward et al., 2011).

Pada studi ini akan dilakukan tinjauan pengaruh sudut kemiringan lereng terhadap angka stabilitas (stability number), Ns berdasarkan kurva Taylor (1937). Kemudian membandingkan nilai Ns tersebut dengan Ns yang diperoleh dari analisis output software Geo5.

\section{TUJUAN}

Tujuan dari penelitian ini adalah mengevaluasi efek pengurangan dimensi mold terhadap nilai California Bearing Ratio (CBR)-unsoaked material crushed limestone Pangandaran, Jawa Barat.

\section{METODOLOGI}

\subsection{Ruang Lingkup}

Ruang lingkup studi adalah sebagai berikut:

a. Skema lereng yang dikaji tampak pada Gambar 1 .

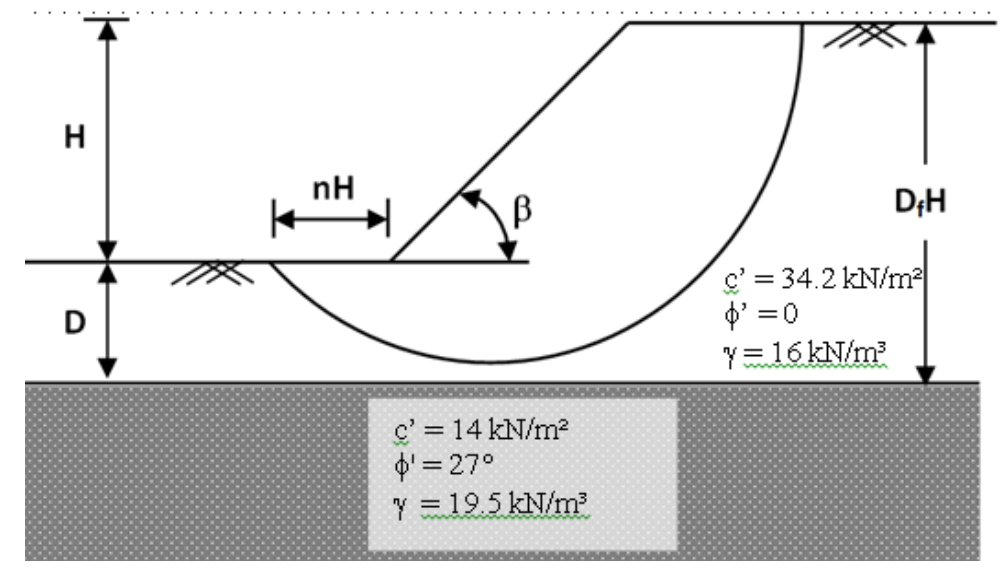

Gambar 1. Skema Lereng Tanah Kohesif 
b. Bagan alir studi tampak pada Gambar 2 .

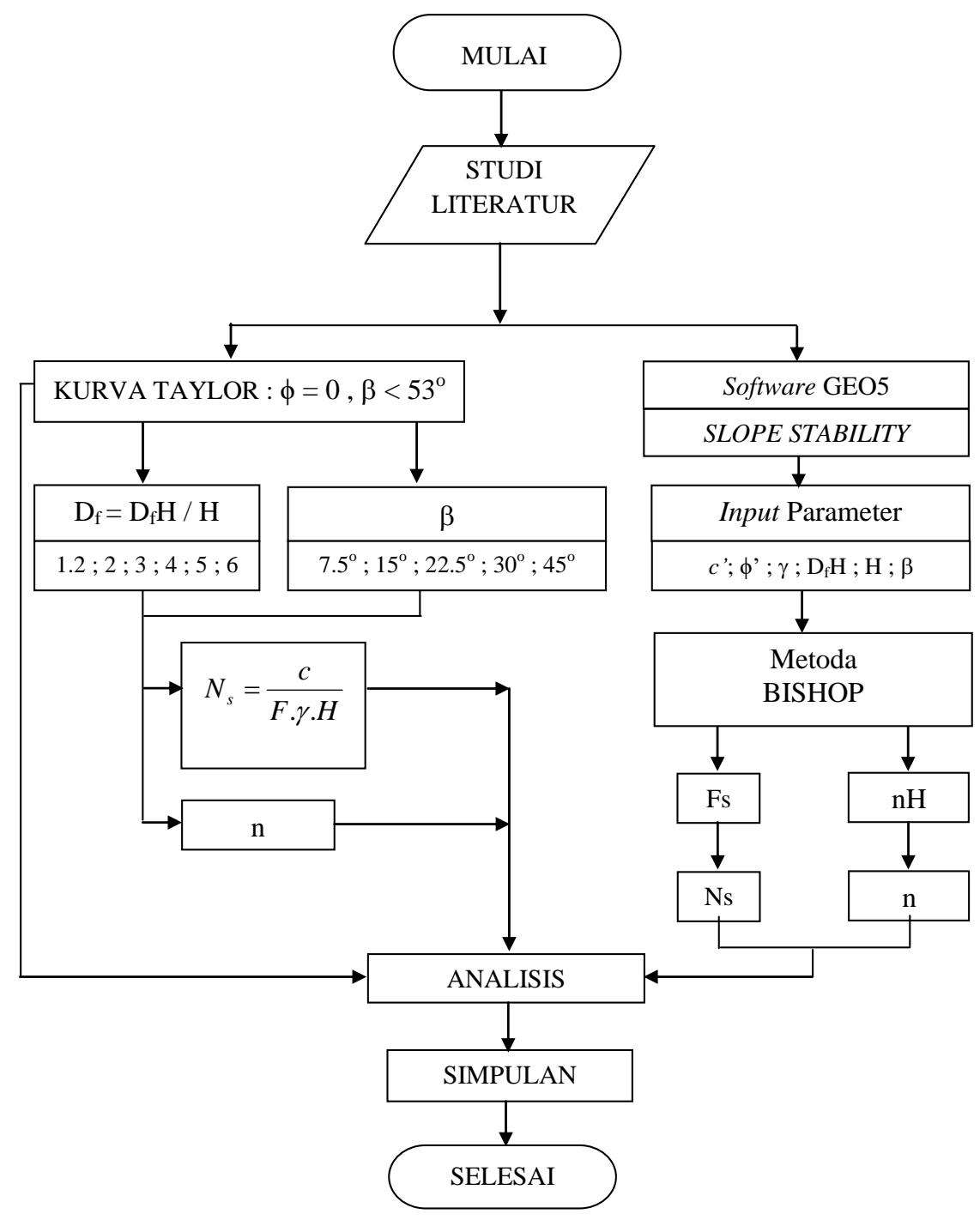

Gambar 2. Bagan Alir Studi

c. Jenis tanah pada lereng yang ditinjau adalah tanah lempung homogen dengan konsistensi medium (medium clay) dengan parameter sebagai berikut: kohesi, $c^{\prime}=34.2 \mathrm{kN} / \mathrm{m}^{2}$, sudut geser dalam, $\phi^{\prime}=0^{\circ}$, dan berat volume, $\gamma=16 \mathrm{kN} / \mathrm{m}^{3}$.

d. Lapisan tanah dasar adalah gravelly clay dengan parameter sebagai berikut: c' $=14 \mathrm{kN} / \mathrm{m}^{2}, \phi^{\prime}=27^{\circ}$, dan $\gamma=19.5 \mathrm{kN} / \mathrm{m}^{3}$.

e. Variasi sudut kemiringan lereng $(\beta)$ adalah : $7.5^{\circ} ; 15^{\circ} ; 22.5^{\circ} ; 30^{\circ} ;$ dan $45^{\circ}$.

f. Ketebalan lapisan medium clay $\left(\mathrm{D}_{\mathrm{f}} \mathrm{H}\right)$ adalah $6.0 \mathrm{~m}$.

g. Tidak ada muka air tanah pada lereng yang ditinjau. 
h. Analisis angka stabilitas pada lereng menggunakan kurva Taylor (1937) dan software Geo5 (V.19 - academic version).

\subsection{Angka Stabilitas berdasarkan Kurva Taylor}

Taylor (1937) telah melakukan pemecahan matematik terhadap analisis stabilitas lereng yang mempunyai kemiringan seragam, dimana faktor keamanan untuk lereng tertentu ditentukan berdasarkan kohesi dan sudut geser dalam (Dep. PU, 2006). Kurva Taylor seperti ditunjukkan pada Gambar 3 merupakan hubungan antara angka stabilitas (stability number), Ns dengan sudut kemiringan lereng untuk berbagai nilai sudut geser dalam.

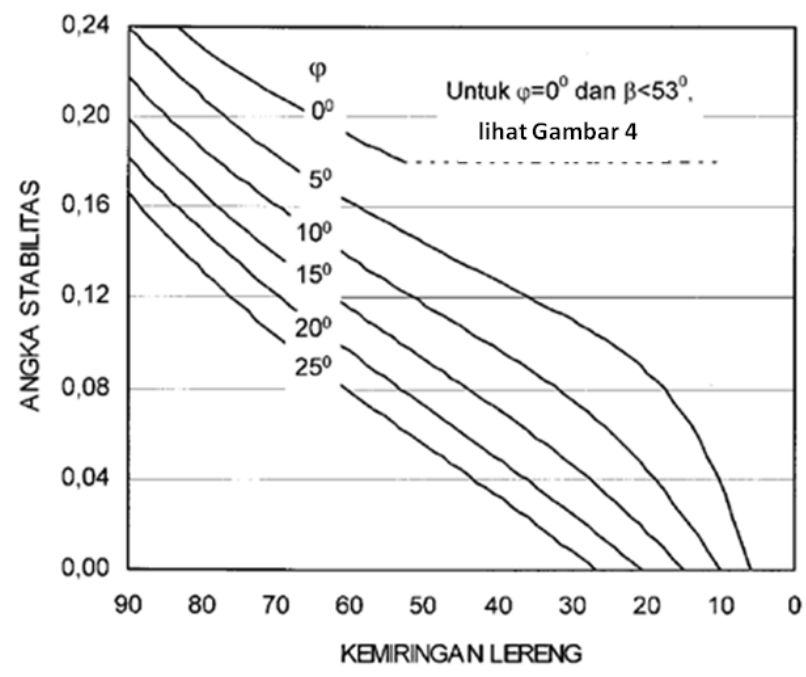

Gambar 3. Kurva Taylor untuk Angka Stabilitas dengan Berbagai Sudut Kemiringan Lereng dan Sudut Geser Dalam Sumber: Dep. Pekerjaan Umum, 2006

Angka stabilitas dapat didefiniskan dengan menggunakan persamaan berikut ini :

$$
\mathrm{Ns}=\frac{c}{F \cdot \gamma \cdot H}
$$

dimana:

$$
\begin{array}{ll}
\mathrm{c} & =\text { kohesi tanah } \\
\mathrm{F} & =\text { faktor keamanan stabilitas lereng } \\
\gamma & =\text { berat volume tanah } \\
\mathrm{H} & =\text { tinggi lereng/kedalaman galian }
\end{array}
$$


Dalam menggunakan Persamaan (1), masing-masing parameter harus menggunakan satuan yang konsisten.

Kurva Taylor yang menunjukkan hubungan antara angka stabilitas dan faktor kedalaman (depth factor), $\mathrm{D}_{\mathrm{f}}$ untuk kondisi $\phi=0^{\circ}$ dan $\beta<53^{\circ}$ tampak pada Gambar 4.

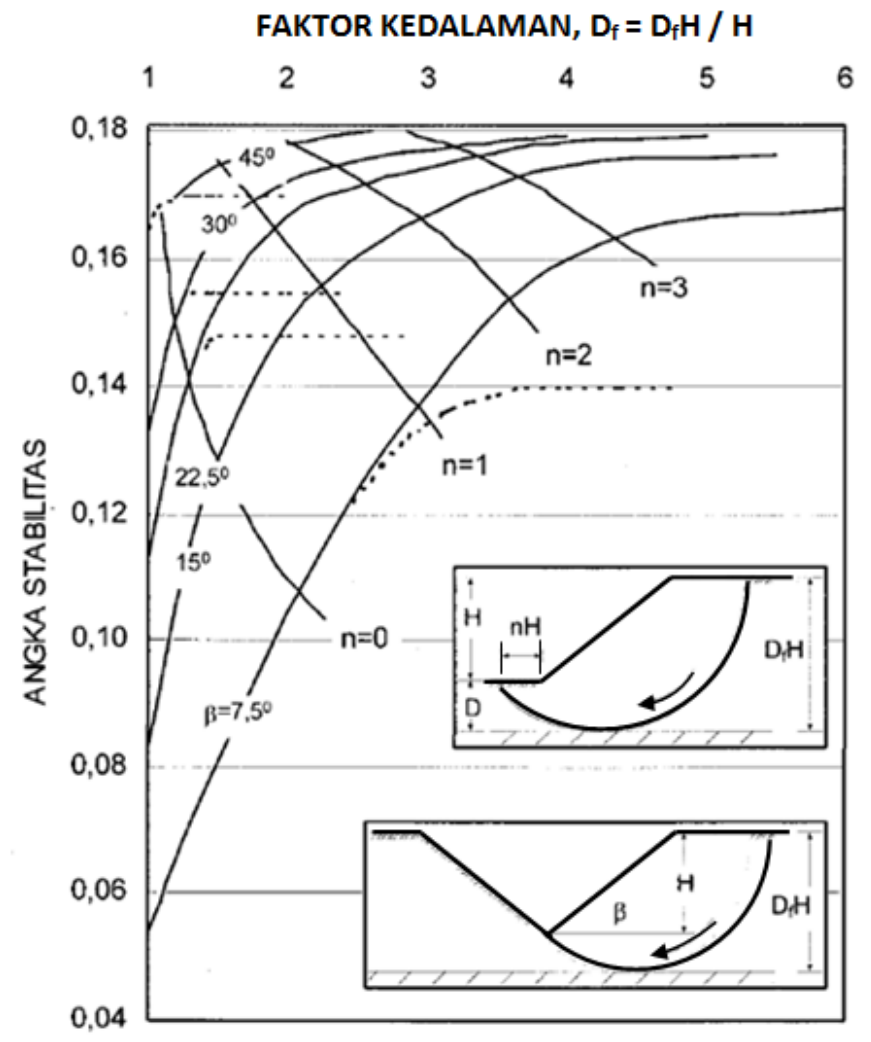

\section{Gambar 4. Kurva Taylor untuk Angka Stabilitas dengan kondisi $\phi=0^{\circ}$ dan $\beta<53^{\circ}$ \\ Sumber: Dep. Pekerjaan Umum, 2006}

\subsection{Analisis Stabilitas Lereng berdasarkan Software Geo5}

Contoh input interface, input list of soils dan contoh output analisis stabilitas lereng berdasarkan software Geo5 untuk kondisi $\beta=30^{\circ}$ dan $D_{f}=2$ tampak berturut-turut pada Gambar 5, Gambar 6 dan Gambar 7.

Gambar 7 menunjukkan bahwa output software Geo5 akan memberikan parameter dan informasi sebagai berikut :

- factor of safety (faktor keamanan)

- lokasi circular slip surface (radius, $\mathrm{R}$ dan center (x ; z)) 

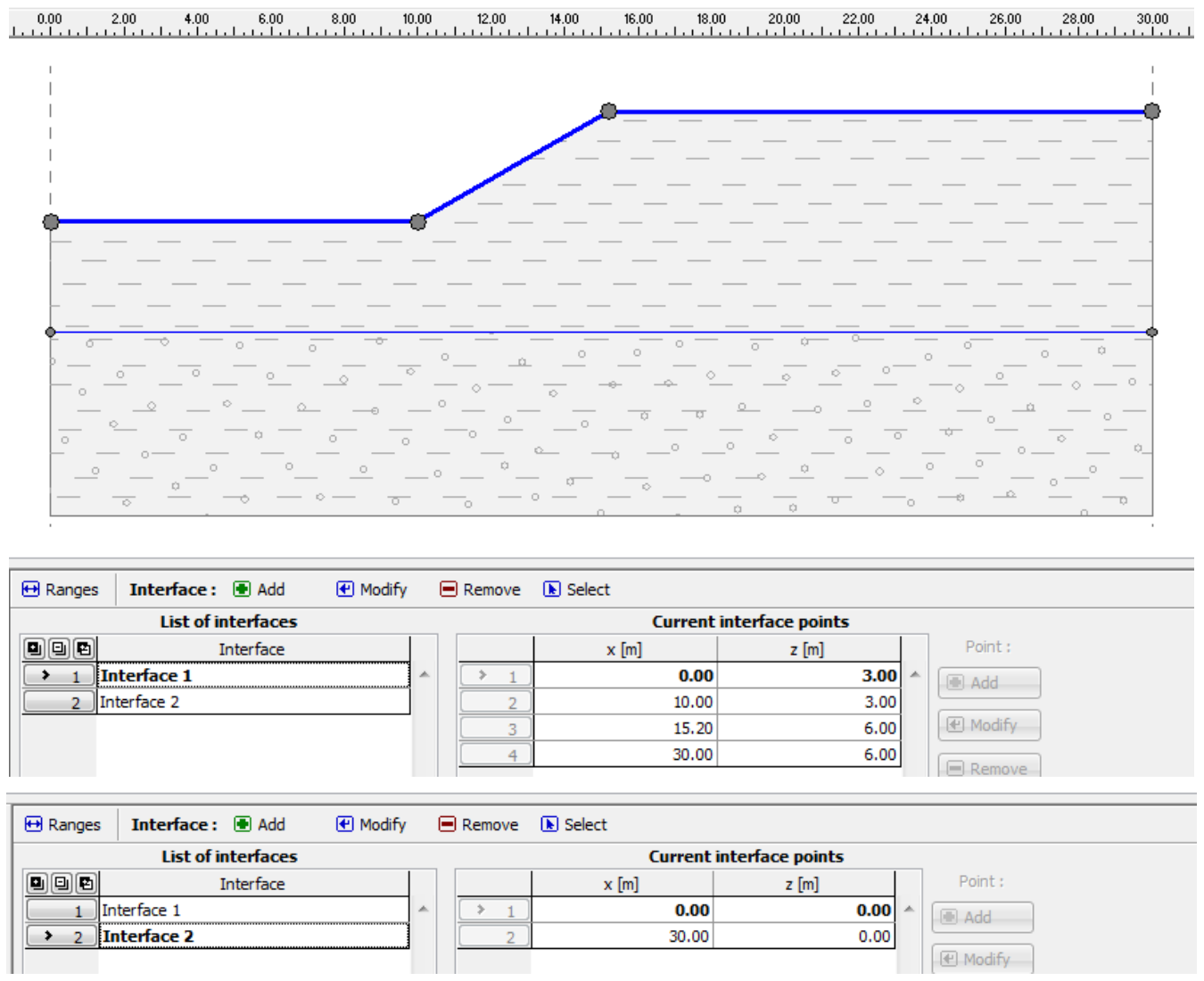

Gambar 5. Contoh Input Interface pada Software Geo5 untuk kondisi $\beta=30^{\circ}$ dan $D_{f}=2$

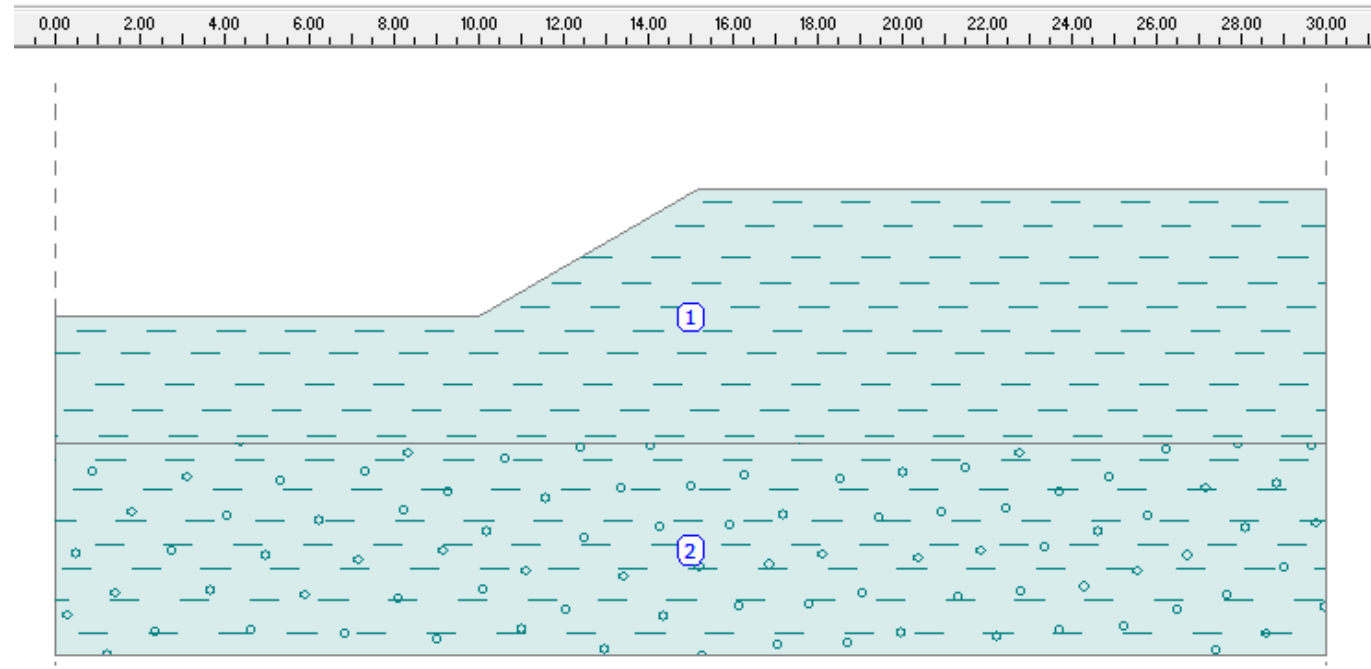

\begin{tabular}{|c|c|}
\hline \multicolumn{2}{|r|}{ List of soils } \\
\hline 부빕 & Soil name \\
\hline$>1$ & Medium Clay \\
\hline 2 & Gravelly clay (CG), consistency stiff $\mathrm{Sr}>0 . \S$ \\
\hline
\end{tabular}

Gambar 6. Contoh Input List of Soils pada Software Geo5 untuk kondisi $\beta=30^{\circ}$ dan $D_{f}=2$ 


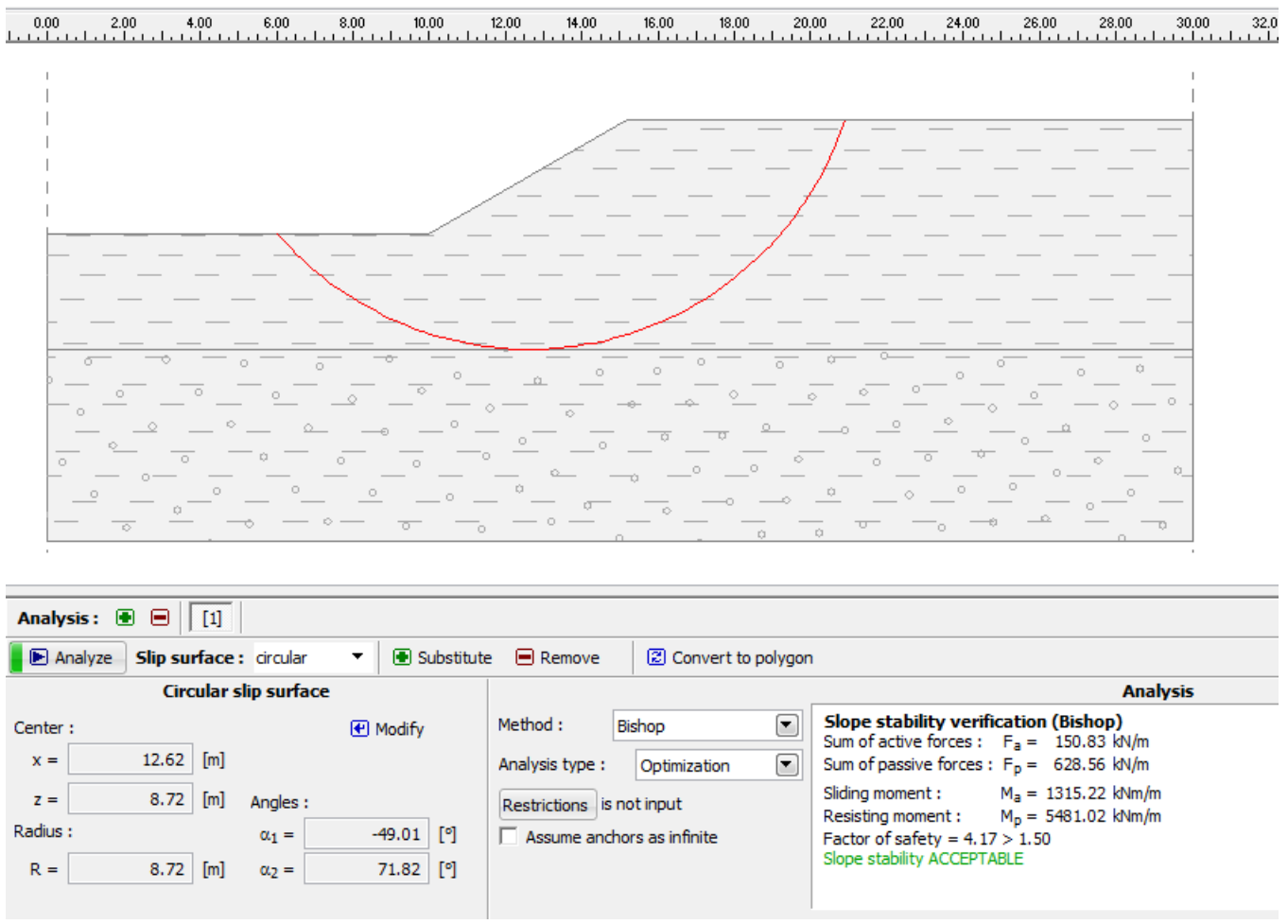

\section{Gambar 7. Contoh Output Software Geo5 untuk kondisi \\ $\beta=30^{\circ}$ dan $D_{f}=2$}

Dengan diketahuinya nilai faktor keamanan dari output software Geo5, maka nilai Ns dapat diperoleh dengan cara hasil perhitungan empiris yang mengacu pada Persamaan (1). Selanjutnya nilai Ns berdasarkan output software Geo5 ini akan dibandingkan dengan Ns yang diperoleh dari kurva Taylor.

\section{HASIL DAN DISKUSI}

Angka stabilitas dan faktor jarak (distance factor) yang diperoleh berdasarkan kurva Taylor (Gambar 4) untuk berbagai sudut kemiringan lereng dan faktor kedalaman yang ditinjau dinyatakan pada Tabel 1 .

Tabel 1 menunjukkan bahwa faktor kedalaman semakin besar maka angka stabilitas akan semakin besar pula. Demikian pula halnya dengan faktor jarak (n). Batasan untuk faktor jarak menurut kurva Taylor adalah: $0<\mathrm{n}<3$. Jika $\mathrm{n}>3$ maka nilai angka stabilitas untuk setiap sudut kemiringan lereng tidak dapat ditentukan. 
Tabel 1. Angka Stabilitas berdasarkan Kurva Taylor

\begin{tabular}{|c|c|c|c|c|c|}
\hline \multirow[b]{2}{*}{$\begin{array}{c}\mathrm{D}_{\mathrm{f}} \mathrm{H} \\
(\mathrm{m})\end{array}$} & \multirow[b]{2}{*}{$\begin{array}{c}\mathrm{H} \\
(\mathrm{m})\end{array}$} & \multirow[b]{2}{*}{$\begin{array}{c}\text { Faktor } \\
\text { Kedalaman } \\
D_{\mathrm{f}}\end{array}$} & \multirow[b]{2}{*}{$\begin{array}{c}\beta \\
(\mathrm{deg})\end{array}$} & \multicolumn{2}{|c|}{ Kurva Taylor } \\
\hline & & & & $\begin{array}{c}\text { Angka } \\
\text { Stabilitas } \\
\text { Ns }\end{array}$ & $\begin{array}{c}\text { Faktor } \\
\text { Jarak } \\
\mathrm{n}=\mathrm{nH} / \mathrm{H}\end{array}$ \\
\hline \multirow{6}{*}{6} & "5.0 & 1.20 & \multirow{6}{*}{45} & 0.1695 & 0.23 \\
\hline & 3.0 & 2.00 & & 0.1777 & 1.92 \\
\hline & 2.0 & 3.00 & & - & - \\
\hline & 1.5 & 4.00 & & - & - \\
\hline & 1.2 & 5.00 & & - & - \\
\hline & 1.0 & 6.00 & & - & - \\
\hline \multirow{6}{*}{6} & 5.0 & 1.20 & \multirow{6}{*}{30} & 0.1510 & 0.02 \\
\hline & 3.0 & 2.00 & & 0.1718 & 1.43 \\
\hline & 2.0 & 3.00 & & 0.1768 & 2.77 \\
\hline & 1.5 & 4.00 & & 0.1790 & - \\
\hline & 1.2 & 5.00 & & - & - \\
\hline & 1.0 & 6.00 & & - & - \\
\hline \multirow{6}{*}{6} & 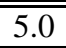 & 1.20 & \multirow{6}{*}{22.5} & 0.1330 & - \\
\hline & 3.0 & 2.00 & & 0.1661 & 1.15 \\
\hline & 2.0 & 3.00 & & 0.1738 & 2.54 \\
\hline & 1.5 & 4.00 & & 0.1780 & - \\
\hline & 1.2 & 5.00 & & 0.1788 & - \\
\hline & 1.0 & 6.00 & & - & - \\
\hline \multirow{6}{*}{6} & "5.0 & 1.20 & \multirow{6}{*}{15.0} & 0.1040 & 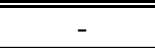 \\
\hline & 3.0 & 2.00 & & 0.1493 & 0.68 \\
\hline & 2.0 & 3.00 & & 0.1662 & 2.06 \\
\hline & 1.5 & 4.00 & & 0.1741 & - \\
\hline & 1.2 & 5.00 & & 0.1758 & - \\
\hline & 1.0 & 6.00 & & - & - \\
\hline \multirow{6}{*}{6} & 5.0 & 1.20 & \multirow{6}{*}{7.5} & 0.0650 & - \\
\hline & 3.0 & 2.00 & & 0.1040 & - \\
\hline & 2.0 & 3.00 & & 0.1383 & 1.09 \\
\hline & 1.5 & 4.00 & & 0.1596 & 2.54 \\
\hline & 1.2 & 5.00 & & 0.1663 & - \\
\hline & 1.0 & 6.00 & & 0.1675 & - \\
\hline
\end{tabular}

Hasil analisis stabilits lereng berdasarkan software Geo5 dengan berbagai sudut kemiringan lereng yang ditinjau pada studi ini dinyatakan pada Tabel 2 hingga Tabel 6. Tabel 2 menunjukkan bahwa untuk $\beta=45^{\circ}$; faktor keamanan meningkat seiring dengan meningkatkannya faktor kedalaman. Kondisi ini berlaku pula untuk $\beta$ lainnya seperti ditunjukkan pada Tabel 3 hingga Tabel 6 . Dari keseluruh sudut kemiringan lereng yang ditinjau pada studi ini, faktor keamanan terendah adalah 2.53 yaitu untuk kondisi $\beta=45^{\circ}$. Selain faktor keamanan, lokasi circular slip surface yaitu radius $(\mathrm{R})$ dan center $(\mathrm{x} ; \mathrm{z})$ untuk setiap $\beta$ dapat diketahui dari output software Geo5. Hal ini merupakan salah satu keunggulan dari analisis stabilitas lereng berdasarkan software Geo5. 
Tabel 2. Hasil Analisis Software Geo5 untuk $\beta=\mathbf{4 5}^{\circ}$

\begin{tabular}{lrrrrrr}
\hline $\mathrm{c}^{\prime}\left(\mathrm{kN} / \mathrm{m}^{2}\right)$ & 34.2 & 34.2 & 34.2 & 34.2 & 34.2 & 34.2 \\
$\gamma\left(\mathrm{kN} / \mathrm{m}^{3}\right)$ & 16 & 16 & 16 & 16 & 16 & 16 \\
$\beta(\mathrm{deg})$ & 45 & 45 & 45 & 45 & 45 & 45 \\
$\mathrm{D}_{\mathrm{f}} \mathrm{H}(\mathrm{m})$ & 6.00 & 6.00 & 6.00 & 6.00 & 6.00 & 6.00 \\
$\mathrm{H}(\mathrm{m})$ & 5.00 & 3.00 & 2.00 & 1.50 & 1.20 & 1.00 \\
$\mathrm{D}(\mathrm{m})$ & 1.00 & 3.00 & 4.00 & 4.50 & 4.80 & 5.00 \\
$\mathrm{D}_{\mathrm{f}}$ & 1.20 & 2.00 & 3.00 & 4.00 & 5.00 & 6.00 \\
\hline $\mathrm{x}(\mathrm{m})$ & 12.48 & 11.47 & 11.01 & 10.74 & 10.62 & 10.56 \\
$\mathrm{z}(\mathrm{m})$ & 7.95 & 8.23 & 8.77 & 9.06 & 9.27 & 9.41 \\
$\mathrm{R}(\mathrm{m})$ & 7.95 & 8.23 & 8.78 & 9.05 & 9.25 & 9.41 \\
$\mathrm{nH}(\mathrm{m})$ & 1.38 & 4.88 & 6.36 & 7.08 & 7.48 & 7.75 \\
Factor of Safety, F & 2.53 & 4.05 & 6.00 & 7.97 & 9.94 & 11.93 \\
\hline $\mathrm{n}$ & 0.276 & 1.628 & 3.181 & 4.718 & 6.232 & 7.753 \\
$\mathrm{Ns}$ & 0.1690 & 0.1759 & 0.1781 & 0.1788 & 0.1792 & 0.1792 \\
\hline
\end{tabular}

Tabel 3. Hasil Analisis Software Geo5 untuk $\beta=30^{\circ}$

\begin{tabular}{lrrrrrr}
\hline $\mathrm{c}^{\prime}\left(\mathrm{kN} / \mathrm{m}^{2}\right)$ & 34.2 & 34.2 & 34.2 & 34.2 & 34.2 & 34.2 \\
$\gamma\left(\mathrm{kN} / \mathrm{m}^{3}\right)$ & 16 & 16 & 16 & 16 & 16 & 16 \\
$\beta(\mathrm{deg})$ & 30 & 30 & 30 & 30 & 30 & 30 \\
$\mathrm{D}_{\mathrm{f}} \mathrm{H}(\mathrm{m})$ & 6 & 6 & 6 & 6 & 6 & 6 \\
$\mathrm{H}(\mathrm{m})$ & 5.00 & 3.00 & 2.00 & 1.50 & 1.20 & 1.00 \\
$\mathrm{D}(\mathrm{m})$ & 1.00 & 3.00 & 4.00 & 4.50 & 4.80 & 5.00 \\
$\mathrm{D}_{\mathrm{f}}$ & 1.20 & 2.00 & 3.00 & 4.00 & 5.00 & 6.00 \\
\hline $\mathrm{x}(\mathrm{m})$ & 14.35 & 12.62 & 12.72 & 11.33 & 10.99 & 10.85 \\
$\mathrm{z}(\mathrm{m})$ & 9.92 & 8.72 & 8.98 & 9.20 & 9.34 & 9.51 \\
$\mathrm{R}(\mathrm{m})$ & 9.93 & 8.72 & 8.99 & 9.21 & 9.34 & 9.51 \\
$\mathrm{nH}(\mathrm{m})$ & 0.01 & 3.96 & 4.76 & 6.59 & 7.17 & 7.52 \\
Factor of Safety, $\mathrm{F}$ & 2.80 & 4.17 & 6.06 & 8.01 & 9.98 & 11.95 \\
\hline $\mathrm{n}$ & 0.003 & 1.321 & 2.382 & 4.394 & 5.977 & 7.523 \\
$\mathrm{Ns}$ & 0.1527 & 0.1709 & 0.1764 & 0.1779 & 0.1785 & 0.1789 \\
\hline
\end{tabular}

Tabel 4. Hasil Analisis Software Geo5 untuk $\beta=22.5^{\circ}$

\begin{tabular}{lrrrrrr}
\hline $\mathrm{c}^{\prime}\left(\mathrm{kN} / \mathrm{m}^{2}\right)$ & 34.2 & 34.2 & 34.2 & 34.2 & 34.2 & 34.2 \\
$\gamma\left(\mathrm{kN} / \mathrm{m}^{3}\right)$ & 16 & 16 & 16 & 16 & 16 & 16 \\
$\beta(\mathrm{deg})$ & 22.5 & 22.5 & 22.5 & 22.5 & 22.5 & 22.5 \\
$\mathrm{D}_{\mathrm{f}} \mathrm{H}(\mathrm{m})$ & 6 & 6 & 6 & 6 & 6 & 6 \\
$\mathrm{H}(\mathrm{m})$ & 5.00 & 3.00 & 2.00 & 1.50 & 1.20 & 1.00 \\
$\mathrm{D}(\mathrm{m})$ & 1.00 & 3.00 & 4.00 & 4.50 & 4.80 & 5.00 \\
$\mathrm{D}_{\mathrm{f}}$ & 1.20 & 2.00 & 3.00 & 4.00 & 5.00 & 6.00 \\
\hline $\mathrm{x}(\mathrm{m})$ & 15.25 & 13.62 & 12.41 & 9.39 & 11.46 & 11.19 \\
$\mathrm{z}(\mathrm{m})$ & 12.05 & 9.41 & 9.17 & 9.40 & 9.54 & 9.53 \\
$\mathrm{R}(\mathrm{m})$ & 12.29 & 9.41 & 9.18 & 9.34 & 9.55 & 9.53 \\
$\mathrm{nH}(\mathrm{m})$ & 0.13 & 3.27 & 5.18 & 8.56 & 6.83 & 7.19 \\
Factor of Safety, F & 3.17 & 4.33 & 6.16 & 8.08 & 10.03 & 11.99 \\
\hline $\mathrm{n}$ & 0.026 & 1.090 & 2.588 & 5.708 & 5.692 & 7.195 \\
$\mathrm{Ns}$ & 0.1349 & 0.1645 & 0.1735 & 0.1764 & 0.1776 & 0.1783 \\
\hline
\end{tabular}


Tabel 5. Hasil Analisis Software Geo5 untuk $\beta=\mathbf{1 5}^{\mathbf{0}}$

\begin{tabular}{lrrrrrr}
\hline $\mathrm{c}^{\prime}\left(\mathrm{kN} / \mathrm{m}^{2}\right)$ & 34.2 & 34.2 & 34.2 & 34.2 & 34.2 & 34.2 \\
$\gamma\left(\mathrm{kN} / \mathrm{m}^{3}\right)$ & 16 & 16 & 16 & 16 & 16 & 16 \\
$\beta(\mathrm{deg})$ & 15 & 15 & 15 & 15 & 15 & 15 \\
$\mathrm{D}_{\mathrm{f}} \mathrm{H}(\mathrm{m})$ & 6 & 6 & 6 & 6 & 6 & 6 \\
$\mathrm{H}(\mathrm{m})$ & 5.00 & 3.00 & 2.00 & 1.50 & 1.20 & 1.00 \\
$\mathrm{D}(\mathrm{m})$ & 1.00 & 3.00 & 4.00 & 4.50 & 4.80 & 5.00 \\
$\mathrm{D}_{\mathrm{f}}$ & 1.20 & 2.00 & 3.00 & 4.00 & 5.00 & 6.00 \\
\hline $\mathrm{x}(\mathrm{m})$ & 17.76 & 15.6 & 13.7 & 12.81 & 12.25 & 11.87 \\
$\mathrm{z}(\mathrm{m})$ & 18.22 & 11.17 & 9.91 & 9.64 & 9.64 & 9.72 \\
$\mathrm{R}(\mathrm{m})$ & 19.12 & 11.17 & 9.91 & 9.65 & 9.65 & 9.72 \\
$\mathrm{nH}(\mathrm{m})$ & 0.55 & 2.02 & 4.25 & 5.36 & 6.10 & 6.63 \\
Factor of Safety, F & 3.92 & 4.76 & 6.41 & 8.25 & 10.16 & 12.10 \\
\hline $\mathrm{n}$ & 0.110 & 0.672 & 2.127 & 3.571 & 5.082 & 6.627 \\
$\mathrm{Ns}$ & 0.1091 & 0.1497 & 0.1667 & 0.1727 & 0.1753 & 0.1767 \\
\hline
\end{tabular}

Tabel 6. Hasil Analisis Software Geo5 untuk $\beta=7.5^{\circ}$

\begin{tabular}{lrrrrrr}
\hline $\mathrm{c}^{\prime}\left(\mathrm{kN} / \mathrm{m}^{2}\right)$ & 34.2 & 34.2 & 34.2 & 34.2 & 34.2 & 34.2 \\
$\gamma\left(\mathrm{kN} / \mathrm{m}^{3}\right)$ & 16 & 16 & 16 & 16 & 16 & 16 \\
$\beta(\mathrm{deg})$ & 7.5 & 7.5 & 7.5 & 7.5 & 7.5 & 7.5 \\
$\mathrm{D}_{\mathrm{f}} \mathrm{H}(\mathrm{m})$ & 6 & 6 & 6 & 6 & 6 & 6 \\
$\mathrm{H}(\mathrm{m})$ & 5.00 & 3.00 & 2.00 & 1.50 & 1.20 & 1.00 \\
$\mathrm{D}(\mathrm{m})$ & 1.00 & 3.00 & 4.00 & 4.50 & 4.80 & 5.00 \\
$\mathrm{D}_{\mathrm{f}}$ & 1.20 & 2.00 & 3.00 & 4.00 & 5.00 & 6.00 \\
\hline $\mathrm{x}(\mathrm{m})$ & 25.58 & 21.21 & 17.57 & 15.73 & 14.7 & 13.76 \\
$\mathrm{z}(\mathrm{m})$ & 36.72 & 22.56 & 14.2 & 11.97 & 11.07 & 10.56 \\
$\mathrm{R}(\mathrm{m})$ & 39.12 & 22.57 & 14.2 & 11.98 & 11.08 & 10.56 \\
$\mathrm{nH}(\mathrm{m})$ & 0.37 & 0.05 & 2.31 & 3.64 & 4.44 & 5.22 \\
Factor of Safety, F & 6.35 & 6.64 & 7.66 & 9.16 & 10.87 & 12.68 \\
\hline $\mathrm{n}$ & 0.074 & 0.017 & 1.155 & 2.424 & 3.696 & 5.218 \\
$\mathrm{Ns}$ & 0.0673 & 0.1073 & 0.1395 & 0.1556 & 0.1639 & 0.1686 \\
\hline
\end{tabular}

Output software Geo5 tidak secara langsung menghasilkan angka stabilitas. Parameter yang diperoleh dari output software Geo5 yang digunakan untuk perhitungan empiris angka stabilitas adalah faktor keamanan. Dengan menggunakan Persamaan (1), angka stabilitas untuk setiap sudut kemiringan lereng dapat ditentukan dan nilainya ditunjukan pada Tabel 2 hingga Tabel 6.

Untuk keseluruhan $\beta$ yang ditinjau, faktor jarak (n) hasil dari analisis output software Geo5 dapat memiliki nilai yang lebih besar dari 3. Kondisi ini tidak sama seperti pada saat analisis dengan kurva Taylor yang membatasi nilai $n(0<n<3)$.

Plot faktor kedalaman dan angka stabilitas untuk berbagai sudut kemiringan lereng yang diperoleh berdasarkan analisis software Geo5 terhadap kurva Taylor tampak pada Gambar 8. 


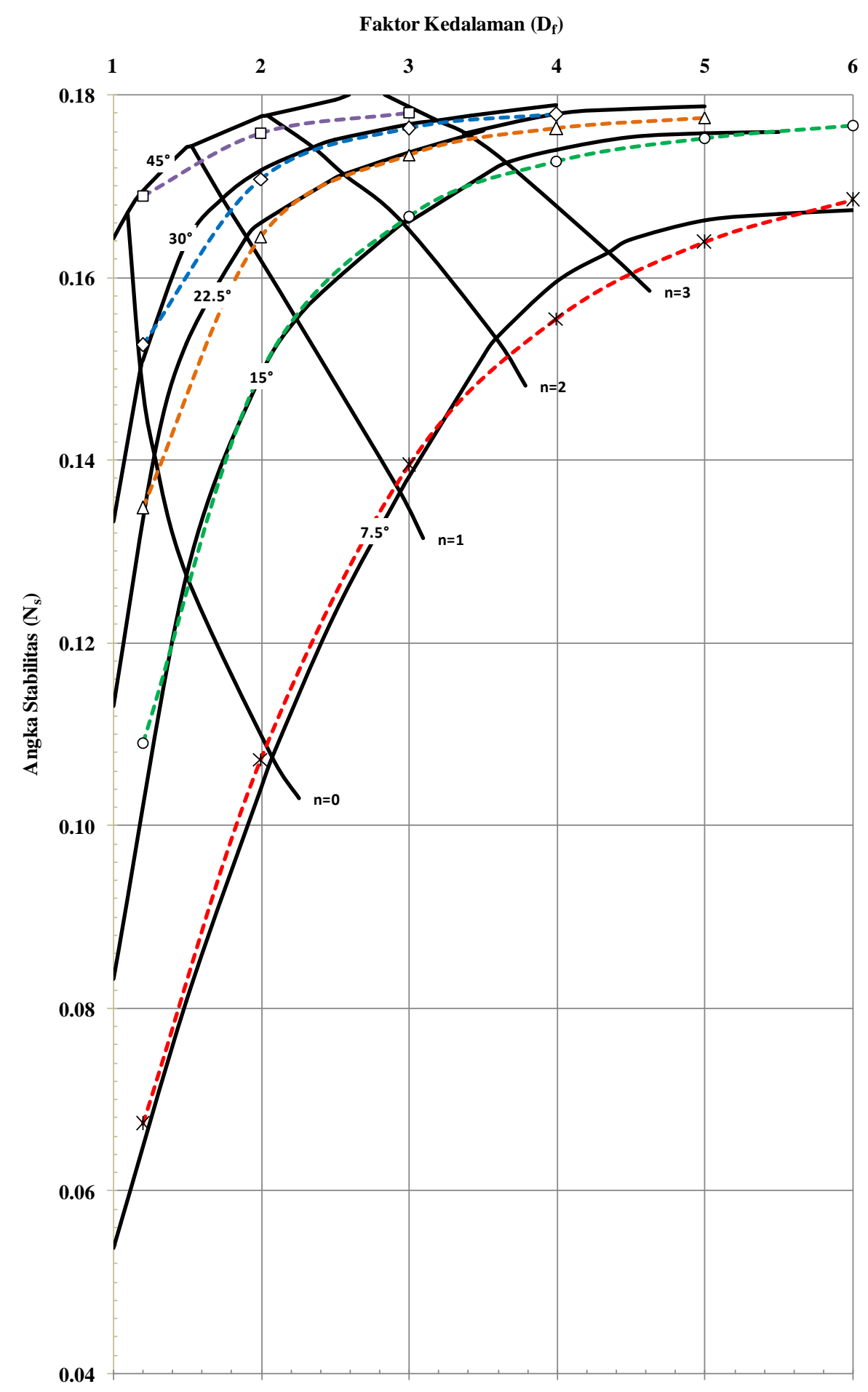

\section{Gambar 8. Plot Faktor Kedalaman dan Angka Stabilitas untuk Berbagai Sudut Kemiringan Lereng berdasarkan Software Geo5 pada Kurva Taylor}

Pengaruh sudut kemiringan lereng terhadap angka stabilitas berdasarkan kurva Taylor dan software Geo5 dinyatakan pada Tabel 6. 
Tabel 6. Pengaruh Sudut Kemiringan Lereng $(\beta)$ terhadap Angka Stabilitas berdasarkan Kurva Taylor dan Software Geo5

\begin{tabular}{|c|c|c|c|c|c|c|}
\hline \multirow[b]{2}{*}{$\begin{array}{c}\text { Faktor } \\
\text { Kedalaman } \\
\mathrm{D}_{\mathrm{f}}\end{array}$} & \multirow[b]{2}{*}{$\begin{array}{c}\beta \\
(\operatorname{deg})\end{array}$} & \multicolumn{2}{|c|}{ Kurva Taylor } & \multicolumn{2}{|c|}{ Geo5 } & \multirow[b]{2}{*}{$\begin{array}{c}\text { Selisih Absolute } \\
\text { Angka Stabilitas } \\
\qquad(\%)\end{array}$} \\
\hline & & $\begin{array}{c}\text { Angka } \\
\text { Stabilitas } \\
\text { Ns }\end{array}$ & $\begin{array}{c}\text { Faktor Jarak } \\
\mathrm{n}=\mathrm{nH} / \mathrm{H}\end{array}$ & $\begin{array}{c}\text { Angka } \\
\text { Stabilitas } \\
\text { Ns }\end{array}$ & $\begin{array}{c}\text { Faktor Jarak } \\
n=n H / H\end{array}$ & \\
\hline 1.20 & \multirow{6}{*}{45} & 0.1695 & 0.23 & 0.1690 & 0.276 & 0.31 \\
\hline 2.00 & & 0.1777 & 1.92 & 0.1759 & 1.628 & 1.01 \\
\hline 3.00 & & - & - & 0.1781 & 3.181 & \\
\hline 4.00 & & - & - & 0.1788 & 4.718 & \\
\hline 5.00 & & - & - & 0.1792 & 6.232 & \\
\hline 6.00 & & - & - & 0.1792 & 7.753 & \\
\hline 1.20 & \multirow{6}{*}{30} & 0.1510 & 0.02 & 0.1527 & 0.003 & 1.10 \\
\hline 2.00 & & 0.1718 & 1.43 & 0.1709 & 1.321 & 0.55 \\
\hline 3.00 & & 0.1768 & 2.77 & 0.1764 & 2.382 & 0.25 \\
\hline 4.00 & & 0.1790 & - & 0.1779 & 4.394 & \\
\hline 5.00 & & - & - & 0.1785 & 5.977 & \\
\hline 6.00 & & - & - & 0.1789 & 7.523 & \\
\hline 1.20 & \multirow{6}{*}{22.5} & 0.1330 & - & 0.1349 & 0.026 & \\
\hline 2.00 & & 0.1661 & 1.15 & 0.1645 & 1.090 & 0.94 \\
\hline 3.00 & & 0.1738 & 2.54 & 0.1735 & 2.588 & 0.17 \\
\hline 4.00 & & 0.1780 & - & 0.1764 & 5.708 & \\
\hline 5.00 & & 0.1788 & - & 0.1776 & 5.692 & \\
\hline 6.00 & & - & - & 0.1783 & 7.195 & \\
\hline 1.20 & \multirow{6}{*}{15.0} & 0.1040 & 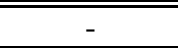 & 0.1091 & 0.110 & \\
\hline 2.00 & & 0.1493 & 0.68 & 0.1497 & 0.672 & 0.26 \\
\hline 3.00 & & 0.1662 & 2.06 & 0.1667 & 2.127 & 0.32 \\
\hline 4.00 & & 0.1741 & - & 0.1727 & 3.571 & \\
\hline 5.00 & & 0.1758 & - & 0.1753 & 5.082 & \\
\hline 6.00 & & - & - & 0.1767 & 6.627 & \\
\hline 1.20 & \multirow{6}{*}{7.5} & 0.0650 & - & 0.0673 & 0.0743 & \\
\hline 2.00 & & 0.1040 & - & 0.1073 & 0.0170 & 3.08 \\
\hline 3.00 & & 0.1383 & 1.09 & 0.1395 & 1.1546 & 0.88 \\
\hline 4.00 & & 0.1596 & 2.54 & 0.1556 & 2.4239 & 2.59 \\
\hline 5.00 & & 0.1663 & - & 0.1639 & 3.6961 & \\
\hline 6.00 & & 0.1675 & - & 0.1686 & 5.2178 & \\
\hline
\end{tabular}

Tabel 6 menunjukkan bahwa sudut kemiringan lereng semakin besar maka angka stabilitas semakin besar untuk setiap faktor kedalaman yang sama. Hal ini berlaku pada baik pada analisis berdasarkan kurva Taylor maupun software Geo5.

Selain itu Tabel 6 menunjukkan juga bahwa selisih absolute angka stabilitas berdasarkan kurva Taylor (1937) terhadap hasil analisis software Geo5 berkisar antara $0.17 \%$ hingga $3.08 \%$ untuk kondisi faktor jarak antara 0 hingga $3(0<\mathrm{n}<$ 3). Untuk angka stabilitas berdasarkan sofware Geo5 dengan kondisi n $>3$ tidak dilakukan perhitungan selisih angka stabilitasnya, karena tidak dapat dilakukan 
penentuan angka stabilitas berdasarkan kurva Taylor untuk kondisi nilai $\mathrm{n}$ yang lebih besar dari 3 .

\section{Simpulan}

Simpulan yang diperoleh dari hasil studi ini adalah sebagai berikut:

1. Salah satu keunggulan analisis stabilitas lereng dengan software Geo5 adalah dapat memberikan informasi mengenai lokasi slip circle atau circular slip surface, dimana hal ini tidak dapat diperoleh dari kurva Taylor.

2. Sudut kemiringan lereng semakin besar, maka angka stabilitas semakin besar untuk setiap faktor kedalaman yang sama. Hal ini berlaku untuk analisis berdasarkan kurva Taylor dan software Geo5.

3. Selisih absolute angka stabilitas berdasarkan kurva Taylor terhadap hasil analisis software Geo5 berkisar antara $0.17 \%$ hingga $3.08 \%$ untuk kondisi faktor jarak antara 0 hingga 3.

4. Angka stabilitas dipengaruhi juga oleh faktor kedalaman, dimana angka stabilitas akan meningkat seiring dengan meningkatkan faktor kedalaman.

\section{DAFTAR PUSTAKA}

1. Das, B.M. and Shoban, K, (2014), Principles of Geotechnical Engineering, SI, $8^{\text {th }}$ Ed., Cengage Learning, Standford, USA.

2. Departemen Pekerjaan Umum - Dirjen. Bina Marga, (2006), Pekerjaan Tanah Dasar - Buku 2, Pedoman Konstruksi dan Bangunan.

3. Look, B.G., (2007), Handbook of Geotechnical Inverstigation and Design Tables, Taylor and Francis, London, UK.

4. Salunkhe, D.P., Chvan, G, Bartakhe, R.N, and Korhavale, P.R., (2017). An Overview on Methods for Slope Stability Analysis, International Journal of Engineering Research \& Technology (IJERT), Vol. 6, 03, pp.528-535.

5. Steward, T., Sivakugan, N., Shukla, S.K., and Das, B.M., (2011). Taylor's Slope Stability Charts Revisited, International Journal of Geomechanics, Vol. 11, No. 4, pp.348-352.

6. Taylor, D.W., (1937). Stability of earth slopes, J. Boston Soc. Civ. Eng., 24,pp.197-246. 